J. Neurol. Neurosurg. Psychiat., 1958, 21, 31.

\title{
A REPORT OF TWO CASES OF THE JUVENILE FORM OF AMAUROTIC FAMILIAL IDIOCY (CEREBROMACULAR DEGENERATION)
}

\author{
BY
}

MICHAEL JEFFERSON and M. L. RUTTER

From the Department of Neurology, Queen Elizabeth Hospital, Birmingham

The cerebral lipidoses are rare diseases, which have few certain links in common beyond the shared facts of disturbed lipid metabolism, progressive mental deterioration coming on early in life, and a heredofamilial pattern of occurrence. In NiemannPick's disease, Gaucher's disease, and xanthomatosis, the lesions of the nervous system are part of a disorder which affects many tissues, though in each of these varieties the intracellular lipid material is different. On the other hand, in the various forms of cerebromacular degeneration (amaurotic familial idiocy), it is generally believed that the nervous system suffers alone. It is for that reason that two cases of amaurotic idiocy are presented, occurring in siblings, since they show some features hitherto only described in association with the generalized lipidoses.

\section{Material}

William and Annette B. are the first and second children in a family of five. Their younger siblings, male and female, not identical twins of 12 , and a sister aged 7, are completely normal. Their parents are of English stock, and not related. On the paternal side, there is a general tendency to pyknic build and a high incidence of early deafness (believed due to otosclerosis) in the female members of the family. On the maternal side, psoriasis is apparently common, chiefly in the females. There is no family history of blindness, dementia, epilepsy, or other neurological disorder and no polydactyly.

Case 1.-William B. aged 19, was admitted to the Midland Nerve Hospital, Birmingham, on October 9, 1956.

His birth was normal, and his mother had been well through pregnancy. Development in infancy and early childhood was uneventful, though there was a tendency to excess weight from an early age. He walked at 13 months, and was talking by 16 months. He went to an elementary school at the age of 5 , where he made average progress until he was 8 , when impairment of vision in both eyes was first noticed. The latter increased, and at $9 \frac{1}{2}$ he had to be transferred to a blind school. By this time some intellectual decline was evident, with forgetful- ness and difficulty in learning, which prevented him mastering even the rudiments of braille. When he was about 16 , he became totally blind, and at the same stage his mental decay seemed to advance more rapidly. He was soon unable to dress himself, to attend to his toilet, or to feed without supervision, and he began to put on more weight. Normal conversation with him became impossible, because he seemed constantly taken up with an imaginary world. In the last two or three years his gait had gradually become abnormal and slightly unsteady, and recently he had often been incontinent in his clothes.

Mental State.-He was talkative, fatuous, and inclined to giggle excessively. He could give his name correctly and, with hesitation, his address and the day and month of his birth but not the year. It was impossible to get any account of his illness from him. He was disorientated in time and place, though sometimes he was aware of being in hospital. He could not answer the simplest questions in general knowledge, and could not add, subtract, write, or spell. He talked at random about non-existent friends, and showed other evidence of frank delusion (for instance, that his father was a doctor). He had no insight into his condition and insisted that he could see, making up descriptions of things and events he was watching. It was uncertain whether this was purely an anosognosic state, or whether he was actively hallucinated.

Physical State.-There was marked general obesity with abdominal and axillary striae, and plethoric facies (Fig. 1). Hair distribution was normal, but his beard was sparse. The external genitalia were normally developed. He was completely blind, with widely dilated pupils unreactive to light. The fundi showed fine scattered dark brown punctate pigmentation in the retinae, with optic atrophy and attenuation of the blood vessels, but no macular abnormality. There was irregular slow nystagmus in all directions of gaze. A slight defect of coordination of movement of all four limbs was present, which was not classically cerebellar, yet was not the result of proprioceptive deficit. Stance was normal, but gait hesitant, small-paced, and slightly unsteady, with arms still at his sides. His speech was slightly spluttering in quality. No other abnormal physical signs were seen, Blood pressure was $160 / 105 \mathrm{~mm}$. Hg. 


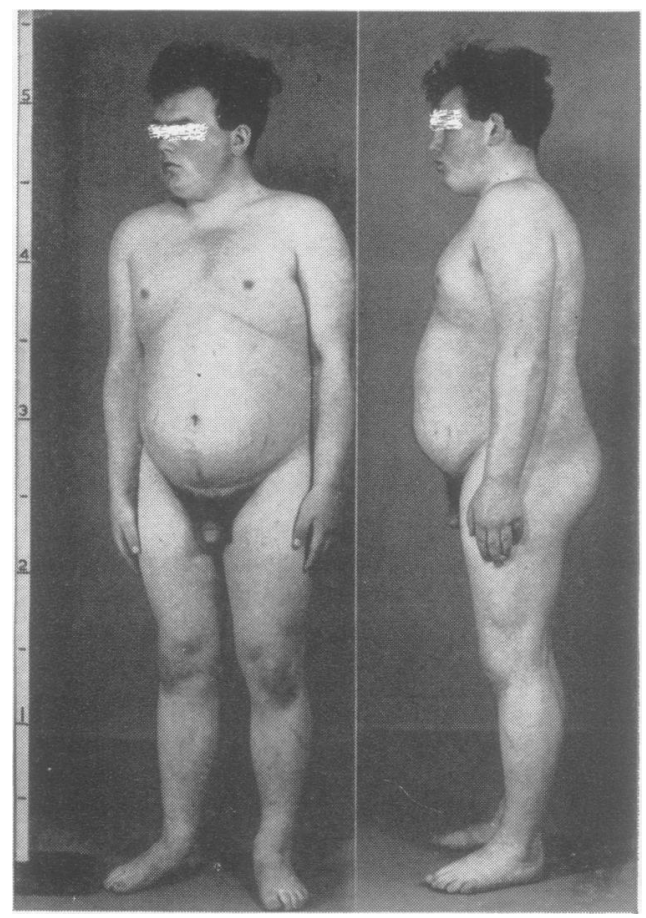

Fig. 1

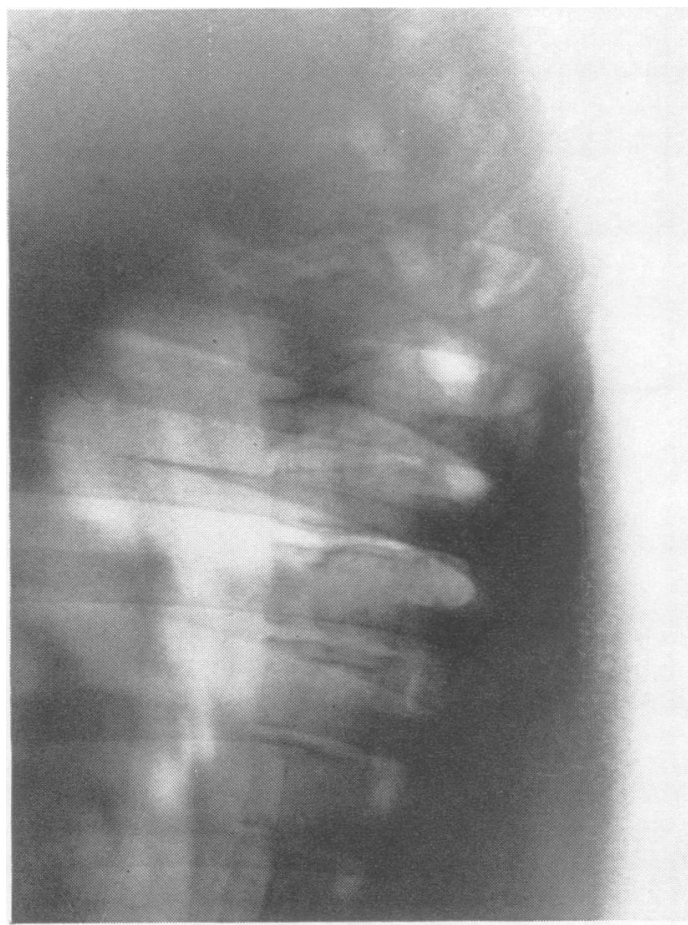

FiG. 2

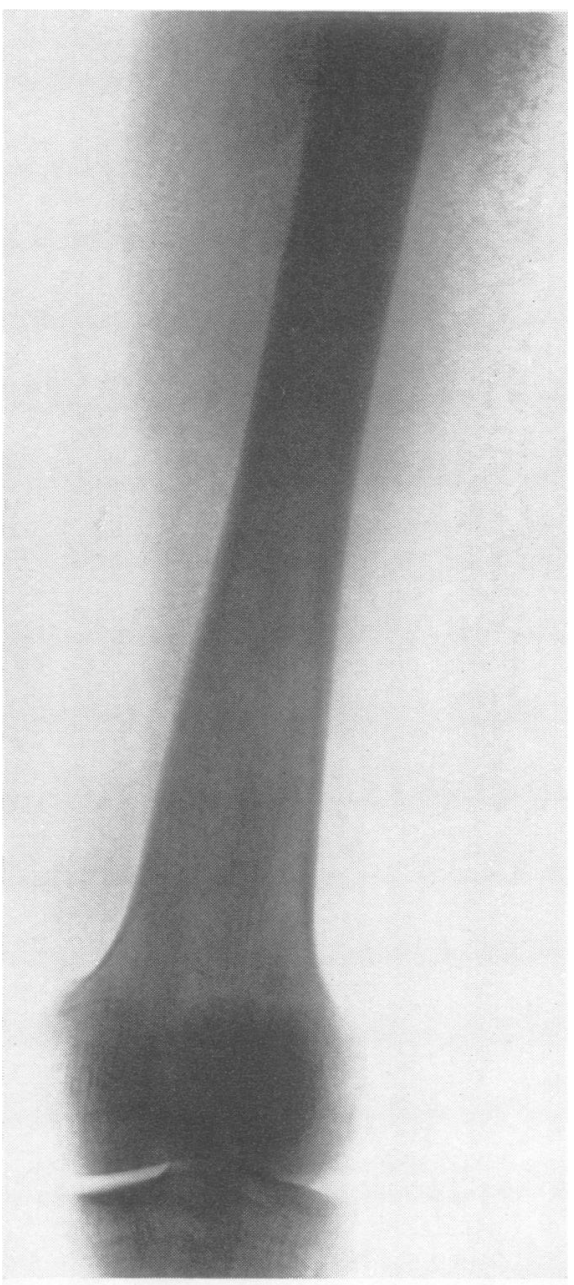

FIG. 3

FIG. 1.-Obese and plethoric appearance, with abdominal striae (Case 1).

Fig. 2.--Radiological appearance of mid and lower dorsal spine; well-marked compression and osteochondritis of vertebral bodies (Case 1).

Fig. 3.-Expansion with cortical thinning of supracondylar one-third of femoral shaft (Case 1). 




FIG. 4.-The E.E.G. of Case 1, demonstrating recurrent high amplitude transients of symmetrical pattern.

Investigations.-Radiographs of the skull and chest were normal, and those of the spine showed flattening of the thoracic vertebrae with osteochondritis (Fig. 2). Radiographs of the limbs showed slight expansion and cortical thinning of the lower ends of both femora (Fig. 3), with cortical thickening in the midshaft of the tibiae.

Generalized osteoporosis was visible in the whole skeleton.

Pneumoencephalography showed symmetrical dilatation of the third and both lateral ventricles, with pooling of air in the subarachnoid spaces.

An E.E.G. showed recurrent high-voltage, slow-wave disturbances, appearing with bilateral synchrony every 2-4 seconds. The background of the record showed an unstable alpha rhythm with a general excess of theta activity (Fig. 4).

Laboratory Studies.-(a) Haemoglobin was 16.2 g. $\%$ $(110 \%)$, R.B.C.s normocytic and normochromic in stained films, W.B.C.s 8,500 (polymorphs $59 \%$, eosinophils $1 \%$, lymphocytes $36 \%$, monocytes $4 \%$ ). (b) The E.S.R. was $8 \mathrm{~mm}$./hr. (Wintrobe). (c) Blood Wassermann and Kahn reactions were negative. (d) Serum sodium was $130 \mathrm{~m} . \mathrm{Eq} . / 1$, potassium $4.6 \mathrm{~m} . \mathrm{Eq} . / 1$, chloride ion $102 \mathrm{~m} . \mathrm{Eq} . / 1$, calcium $12.4 \mathrm{mg} . / 100 \mathrm{ml}$. (e) The serum copper level was $133 \mu \mathrm{g} . / 100 \mathrm{ml}$. and (f) serum iron (i) 233 and (ii) $177 \mu \mathrm{g} . / 100 \mathrm{ml}$. (two separate estimations). (g) Liver function tests (two separate estimations) gave: serum albumin (i) 5.4 and (ii) $5.0 \mathrm{~g} . / 100 \mathrm{ml}$.; serum globulin (i) 2.5 and (ii) $2.1 \mathrm{~g} . /$ $100 \mathrm{ml}$.; gamma globulin (alcohol method) (i and ii)
$1.0 \mathrm{~g} . / 100 \mathrm{ml}$. (ammonium sulphate method) (i) 2.2 and (ii) 2.0 g. $/ 100 \mathrm{ml}$; zinc sulphate turbidity (i) 5.0 and (ii) 4.0 units, zinc sulphate flocculation (i) and (ii) +++ ; thymol turbidity (i) 2.0 and (ii) 1.0 units, thymol flocculation (i) and (ii) negative; colloidal gold (Patterson) (i and ii) 2, (Maclagan) (i and ii) negative; van den Bergh (direct reaction) ( $\mathrm{i}$ and ii) positive, (indirect reaction) (i and ii) positive; serum bilirubin (i) $2 \cdot 1$ and (ii) $1 \cdot 1 \mathrm{mg} . / 100 \mathrm{ml}$.; serum alkaline phosphatase (i) 8.3 and (ii) 5.5 units/ $100 \mathrm{ml}$.; cephalin cholesterol (i and ii) negative, serumfree cholesterol (i) 90 and (ii) $60 \mathrm{mg} . / 100 \mathrm{ml}$., ester cholesterol (i) 140 and (ii) $150 \mathrm{mg} . / 100 \mathrm{ml}$. (h) Faecal fat excretion in 72 hours was $6 \mathrm{~g}$. (i) Urinary 17-ketosteroid excretion was $6 \mathrm{mg}$. $/ 24 \mathrm{hr}$., 17-hydroxysteroid excretion $14 \mathrm{mg} . / 24 \mathrm{hr}$. (j) Urinary amino-acid chromatogram: glycine +++ , serine ++ , glutamic acid + , aspartic acid trace, lysine trace, cystine + , glutamine + , arginine ++ , alanine ++ , valine trace, phenylalamine trace (excretion pattern probably within normal limits). (k) Cerebrospinal fluid pressure and manometrics normal; protein $53 \mathrm{mg} . / 100 \mathrm{ml}$., globulin (Pandy) trace, (Nonne-Apelt) negative, Lange 1111000000; cytology less than 1 white cell/c.mm.; Wassermann reaction negative. ( $l$ ) Urine no albumin or sugar.

Case 2.-Annette B., aged 16, was admitted to the Midland Nerve Hospital, Birmingham, on October 21, 1956.

Like her brother, her birth and early development were quite normal, and she walked and talked at 11 and 14 months respectively. Her eyes were examined at the age of 7 , and are known to have been normal then. 




Fig. 5



FIG. 6

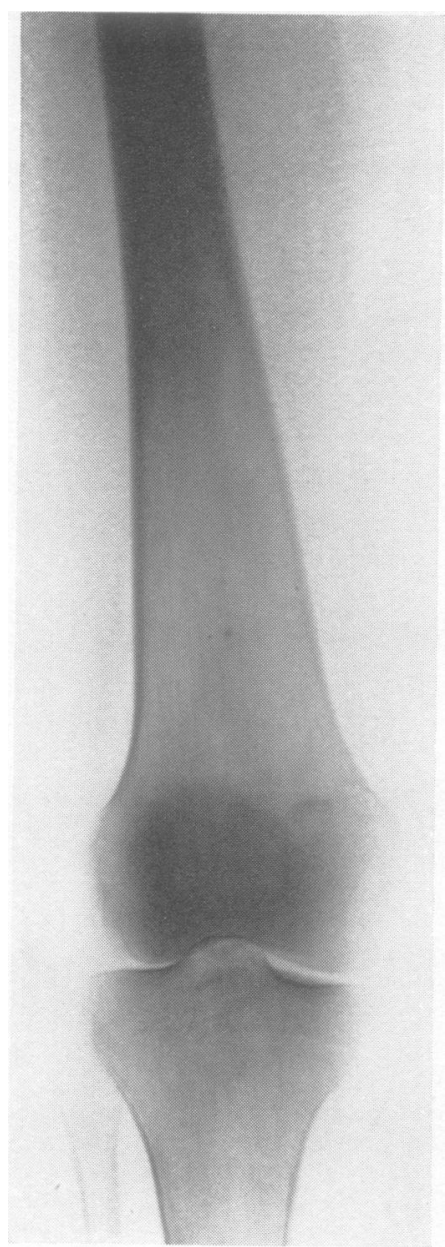

FIG. 7

FIG. 5.-Obesity and habitual posture (Case 2).

FIG. 6.-Radiological changes (Case 2) in lower midthoracic spine for comparison with Fig. 2.

Fig. 7.-Appearance of the femur, showing typical flask shape (Case 2). 
However, at the age of 9 visual failure began, and had advanced sufficiently to necessitate transfer to a blind school at 11. The onset of intellectual deterioration was probably at about this time, but unlike William she was able to learn braille. She continued to be able to read it, though never proficiently, until she was 15 , when it became obvious that she was increasingly forgetful and slow in comprehension. Tasks which she could manage before were now too much, and she became labile in mood, and often tearful. All the time she steadily became increasingly blind.

When she was 12 , she developed a valgus deformity of the left foot. Several manipulations were ineffective, and later peroneal tenotomy was done with only partial success. About the same time she began to put on weight, and to become round-shouldered. The menarche was at 14, and the periods have been regular since.

Mental State.-She was shy and reticent, and frequently wept both during questioning and when on her own in the ward. She was correctly orientated for time and place, and had a sufficient store of general knowledge to name, for example, the Prime Minister and the capital city of Great Britain. She could spell out her name and address, and simple words of up to four or five letters, but was unable to do even the simplest arithmetic. Her power of concentration was poor, and it was impossible to get a clear account of her illness from her.

Physical State.-She was an obese girl with abdominal striae and marked dorsal kyphosis (Fig. 5). Hair distribution, breast development, and external genitalia were normal. She had left pes valgus.

Visual acuity was difficult to assess, but was probably little more than light-dark discrimination. The pupils were mid-dilated and reacted imperfectly to light. Ophthalmoscopy revealed scattered fine dark pigmentation in both retinae with attenuated vessels and somewhat pale discs. There was irregular coarse nystagmus in lateral gaze, and some defect of coordination of the limbs. Her gait was slouching, with short, cautious steps, and the arms held still. She had no other physical abnormalities. Blood pressure was $150 / 80 \mathrm{~mm}$. $\mathrm{Hg}$.

Investigations.-Radiographs of the skull and chest were normal, and of the spine showed definite mid and lower thoracic osteochondritis (Fig. 6). Those of the limbs showed the lower ends of femora to be flask- shaped (Fig. 7). The middle phalanges of the fingers were rather short, with partial fusion of the capitates and hamates. The patient had mild generalized skeletal osteoporosis.

Pneumoencephalography showed slight generalized dilatation of the ventricular system, particularly at the trigone.

An E.E.G. showed repeated slow-wave events of high amplitude similar to those seen in the brother's record, but less regular in occurrence, and tending to last longer (Fig. 8).

Laboratory Studies.-(a) Haemoglobin was $14.8 \mathrm{~g} . \%$ $(100 \%)$, R.B.C.s normocytic and normochromic in films, W.B.C.s 13,000 (polymorphs $80 \%$, eosinophils $1 \%$, lymphocytes $18 \%$, basophils $1 \%$ ). (b) The E.S.R. was $11 \mathrm{~mm}$./hr. (Wintrobe). (c) The blood Wassermann and Kahn reactions were negative. (d) Serum sodium was $131 \mathrm{~m} . \mathrm{Eq} . / 1$, potassium $4.1 \mathrm{~m} . \mathrm{Eq} . / 1$, chloride ion $103 \mathrm{~m}$. Eq. $/ 1$., calcium $12.4 \mathrm{mg} . / 100 \mathrm{ml}$., phosphorus $3.3 \mathrm{mg} . / 100 \mathrm{ml}$. (e) Serum copper was $139 \mu \mathrm{g} . / 100 \mathrm{ml}$. and $(f)$ serum iron $105 \mu \mathrm{g} . / 100 \mathrm{ml}$. $(g)$ Liver function tests gave: serum albumin $5 \cdot 1 \mathrm{~g} . / 100 \mathrm{ml}$.; serum globulin $2.6 \mathrm{~g}$. $/ 100 \mathrm{ml}$.; gamma globulin (alcohol method) $1.7 \mathrm{~g} .100 \mathrm{ml}$. (ammonium sulphate method) $2.5 \mathrm{~g} . /$ $100 \mathrm{ml}$; zinc sulphate turbidity 6.0 units, zinc sulphate flocculation ++++ ; thymol turbidity $2 \cdot 0$ units, thymol flocculation negative; colloidal gold (Patterson) 1, (Maclagan) negative; van den Bergh (direct reaction) positive, (indirect reaction) faintly positive; serum bilirubin less than $0.5 \mathrm{mg} . / 100 \mathrm{ml}$; serum alkaline phosphatase 6.1 units; cephalin cholesterol negative; serum-free cholesterol $60 \mathrm{mg}$. $/ 100 \mathrm{ml}$., ester cholesterol $80 \mathrm{mg}$. $/ 100 \mathrm{ml}$. (h) Faecal fat excretion in 72 hours was $19 \cdot 1 \mathrm{~g}$. (i) Urinary 17-ketosteroid excretion was $4 \mathrm{mg}$. $/ 24 \mathrm{hr}$., 17-hydroxy-steroid excretion $19 \mathrm{mg}$./24 hr., gonadotrophin excretion less than 5 mouse units $/ 24 \mathrm{hr}$. (j) Urinary amino-acid chromatogram: tyrosine trace, alanine + , threonine trace, glutamic acid trace, glycine ++ , serine ++ , aspartic acid trace, cystine trace, glutamine trace (excretion pattern normal). (k) C.S.F. pressure and manometrics normal; protein $24 \mathrm{mg} . / 100 \mathrm{ml}$., globulin (Pandy) trace, (Nonne-Apelt) negative, Lange 1110000000; cytology less than 1 white cell/c.mm.; Wassermann reaction negative. (l) Urine no albumin or sugar.



FIG. 8.-Large slow-wave interruptions in the E.E.G. of Case 2, less frequent but of more variable duration than in Case 1. 


\section{Discussion}

There are two main types, one infantile and the other juvenile, of amaurotic familial idiocy, which are clinically distinct, though their underlying pathology is the same. The first is the form long ago remarked on by Tay (1881) and Sachs (1887), which comes on usually at about 3 months of age, and particularly but not exclusively affects Jews; it runs its course to death by the second or, at latest, the third year of life. Sub-variants of it exist, either congenital (Norman and Wood, 1941) or late infantile (Bielschowsky, 1914; Greenfield and Nevin, 1933) in onset. The second, and perhaps less wellknown, form is that often associated with the name of Spielmeyer (1906) and Vogt (1905), though earlier descriptions were given independently by Batten (1903) and Mayou (1904) and later conjointly (Batten and Mayou, 1915). It appears between the ages of 5 and 14. It presents no racial predilection, is not marked clinically by the cherry-red macular spot so characteristic of the infantile type, the fundi showing diffuse pigmentation instead. The disease is also much slower in its evolution, and its inexorable march to mental and physical inanition covers a span of several years.

The two cases reported here are clear examples of the juvenile sort. Their ophthalmoscopic appearances are quite typical, and correspond closely with the descriptions given by earlier writers (Batten, 1903; Mayou, 1904; Nardin and Cunningham, 1923; Greenfield and Holmes, 1925; Sjögren, 1931; Norman, 1935; Dide and van Bogaert, 1938; Hoffman, 1956). The retinal pigmentation usually is macular or perimacular in situation initially, but sometimes may begin more peripherally; it is at first very fine and dust-like, later tending to become denser from coalescence of granules, and indeed the fundal appearance can finally closely resemble retinitis pigmentosa. The optic discs commonly develop atrophic change with pallor, and attenuation of the retinal arteries and veins is the rule. The macula may in some cases be discoloured. Although it is not invariable, the precedence of visual over mental changes in point of time is the usual order of events, as in our cases.

The emotional lability, impoverishment of learning and memory, fantasies, delusions, and possible hallucinations, all shown clearly in Case 1 and less floridly in Case 2, are features which match accounts of the dementing process given before (Schob, 1924; Sjögren, 1931; Marinesco, 1934; Norman, 1935; FitzJerrell and Neuchiller, 1938; Levy and Little, 1940; Lubin and Marburg, 1943; Hoffman, 1956) though they cannot be taken to represent a pathognomonic constellation in themselves.

With regard to neurological signs, pupillary sluggishness or fixity to light and nystagmus are both common at a relatively early stage or illness, and were present in our cases. It is likely that the deficient light reaction of the pupils (complete in Case 1 who was blind, and partial in Case 2) is accounted for retinal sensory ganglion cell degeneration, rather than an index of midbrain damage. The nystagmus too might be similarly explained because it had the irregular oscillatory quality, quasi searching, that may be met in the blind or $\stackrel{0}{\rightarrow}$ near-blind of long standing. However, a cerebellar factor cannot be discounted, in view of the damage to the cerebellum which is a recognized pathological characteristic of cerebromacular degeneration, especially of its juvenile variety (Frenkel and Dide, 1913; Greenfield and Holmes, 1925; Dide and van Bogaert, 1938). Both patients also showed slight clumsiness of coordination of their limbs, and a disturbance of their gait, which looked hesitant, slovenly, and a little unsteady. It was difficult to be sure whether these were more than a simple result of lack of sight, or again significant of cerebellar deficit. However, such signs have been noticed by other writers (Greenfield and Holmes, 1925; Sjögren 1931; Levy and Little, 1940; Lubin and Marburg 1943), as well as the full-blown cerebellar syndrom $\vec{\Phi}$ which affected the cases of Frenkel and Dide (1913) There was no evidence of pyramidal, extrapyramidal, or sensory disorder in our cases, though aq extensor plantar or mild Parkinsonian sign can occur relatively early, and in the terminal stage there may be complete general paralysis with rigidity resembling the decerebrate state. Nor had either ever had fits, though reference to the literature makes it clear that they are a common manifestation, and death in status epilepticus not an unusual event.

There are relatively few accounts of the E.E.G. changes in amaurotic familial idiocy, but slow wave (delta) dysrhythmia, with and without spikes, has been mentioned by Kornmüller and Janzen (1939), Levy and Little (1940), Lubin and Marburg (1943), and Bjelkhagen (1950). Cobb, Martin, and Pampiglione (1952) consider that the characteristic trace of the cerebral lipidoses in general is one marked by many transients of high amplitude and usually triphasic form, irregularly recurring with bilateral synchrony and diffuse distribution, together with a continuous irregular mixture of waves at $1 \frac{1}{2}$ to $6 \mathrm{c}$./sec., and the records of our cases correspond closely to this pattern.

The radiological findings in both patients are interesting. There is little particular comment in the literature on the radiology of amaurotic familial idiocy, such references as there are being of a negative kind, and though Levy and Little (1940), for instance, noted an abnormal spinal posture in $\mathrm{I}$ (1) $\underline{\omega}$ 으

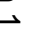

$$
\text { 送 }
$$
$\frac{1}{2}$ . . 
their case, no radiographic report was given. However, a number of radiological studies have been made in Gaucher's disease. According to Gordon (1950), bony changes in the condition were first described as a pathological entity by Risel in 1909, and later, more comprehensively, by Pick (1933); from the radiological point of view, the first complete studies were those of Klercker (1927) and Junghagen (1926). The chief signs are generalized osteoporosis, destruction and compression affecting long bones of the limbs but also the vertebrae and pelvis with formation of large and small worm-eaten defects in the spongiosa, and widening of the lower ends of the femora just above the condyles with thinning of the bony cortex. This femoral abnormality has been likened to the shape of an inverted Erlenmeyer flask and has been described by many writers as a regular, as well as an early, sign (Fischer, 1928; Welt, Rosenthal, and Oppenheimer, 1929; Reed and Sosman, 1942; Snapper, 1943), and flattening of the vertebrae with osteochondritis, though not invariable, is also a common finding. The presence of both these characteristics in the sibs reported here suggests that there may in fact be involvement of the skeletal system by lipid deposition in cerebromacular disease, just as in Gaucher's disease, and hence that there is a closer relationship between this condition and the other lipidoses than has been considered up to now.

Biochemical abnormalities have often been sought, but with little success. It is generally accepted that there may be a rise in the total protein content of the cerebrospinal fluid, with some increase in the globulin component (Levy and Little, 1940), and such was evident in Case 1, although not in Case 2. Both sibs were obese, a point which Ritter (1932), Norman (1935), and Levy and Little (1940) referred to in their examples. Both were also definitely hyperpietic for their age, and with the cutaneous striae and facial plethora as well as the obesity, their general appearance showed something approximating to a Cushing syndrome, a feature which has not been commented on by others. However, neither had other outward marks of endocrine dysfunction, and there was no deviation from the physiological in their urinary steroid excretion or (in the case of the girl) gonadotrophin output.

We were unable to detect any anomaly in their general electrolyte pattern, in their serum iron or copper levels, or signs of amino-aciduria or faulty intestinal absorption of fat. Nevertheless, in both there was an unequivocal rise in the serum gamma globulin concentration, witnessed quantitatively by the alcohol and ammonium sulphate estimations, and also by the results of zinc sulphate turbidity and flocculation tests. The significance of this phe- nomenon is not clear, and so far as we are aware it has not been reported before. Like the radiological signs and the Cushing characteristics, however, it suggests the existence of a bodily disorder in amaurotic familial idiocy which is not simply restricted to the retinae and central nervous system.

These two cases throw no light on the manner of inheritance of the disease, nor on its fundamental cause. It did not seem justifiable to resort to cerebral biopsy to get material for routine pathological study or histochemistry.

\section{Summary}

Two examples of juvenile familial amaurotic idiocy are presented. They were extensively investigated from radiological, biochemical, and electroencephalographic angles. Radiological changes were found in the long bones and spine not previously recorded in this disease, which correspond to those seen in Gaucher's disease, and therefore suggest that the lipid disorder may be widespread rather than restricted to cerebro-retinal neurones. Both also showed signs of Cushing's syndrome, and raised serum gamma globulin, neither reported before.

\section{REFERENCES}

Batten, F. E. (1903). Trans. ophthal. Soc, U.K., 23, 386. and Mayou, M. S. (1915). Proc. roy. Soc. Med., 8, (Neurol Sect.), Pt. 3, 70.

Bielschowsky, M. (1914). Dtsch. Z. Nervenheilk., 50, 7.

Bjelkhagen, I. (1950). Acta paediat. (Uppsala), 39, 445.

Cobb, W., Martin, F., and Pampiglione, G. (1952). Brain, 75, 343

Dide, M., and van Bogaert, L. (1938). Rev. neurol. (Paris), 69, 1.

Fischer, A. W. (1928), Fortschr. Röntgenstr., 37, 158.

FitzJerrell, H. B., and Neuchiller, B. B. (1938). Illinois med. J., 74 456 .

Frenkel, H., and Dide, M. (1913). Rev. neurol. (Paris), 25, 729.

Gordon, G. L. (1950). Amer. J. Med., 8, 332.

Greenfield, J. G., and Holmes, G. (1925). Brain, 48, 183

, and Nevin, S. (1933). Trans. ophthal. Soc. U.K., 53, 170.

Hoffman, J. (1956). Amer. J. Ophthal., 42, 15.

Junghagen, S. (1926). Acta radiol. (Stockh), 5, 506

Klercker, K. Olaf (1927). Acta paediat. (Uppsala), 6, 302

Kornmüller, A. E., and Janzen, R. (1939). Z. ges. Neurol. Psychiat. $166,287$.

Levy, S., and Little, O. A. G. (1940). Arch. Neurcl. Psychiat. (Chicago), 44, 1274.

Lubin, A. J., and Marburg, O. (1943). Ibid., 49, 559.

Marinesco, G. (1934). Rev. Oto-neuro-ophtal., 12, 39.

Mayou, M. S. (1904). Trans. ophthal. Soc. U.K., $24,142$.

Nardin, W. H., and Cunningham, R. S. (1923). Amer. J. Ophthal., 6, 476 .

Norman, K. M. (1935). J. Neurol. Psychopath., 15, 219.

, and Wood, N. (1941). J. Neurol.Psychiat., 4, 175.

Pick, L. (1933). Amer. J. med. Sci., 185, 453.

Reed, J., and Sosman, M. C. (1942). Radiology, 38, 579.

Risel, W. (1909). Beitr. path. Anat., 46, 241.

Ritter, F. H. (1932). Z. ges. Neurol. Psychiat., 141, 402.

Sachs, B. (1887). J. nerv. ment. Dis., 14, 541 . Schob, G. K. (1924). Congenitale, früherworbene und heredofamiliäre
organische Nervenkrankheiten. In Kraus, F., and Brugsch, T.: Spezielle Pathologie und Therapie innerer Krankheiten, Band 10, teil 3, p. 789. Urban and Schwarzenberg, Berlin.

Sjögren, T. (1931). Hereditas (Lund), 14, 197.

Snapper, I. (1943). Medical Clinics on Bone Diseases. Interscience, New York.

Spielmeyer, W. (1906). Neurol. Zbl., 25, 51.

Tay, W. (1881). Trass. ophthal. Soc. U.K., 1, 56

Vogt, H. (1905). Mschr. Psychiat. Neurol., 18, $16 \mathrm{i}$ and 310.

Welt, S., Rosenthal, U., and Oppenheimer, B. S. (1929). J. Amer. med. A.s., 92, 637. 